\title{
Optical monitoring of brain function in vivo: from neurons to networks
}

\author{
Olga Garaschuk • Ruxandra-Iulia Milos • \\ Christine Grienberger • Nima Marandi • \\ Helmuth Adelsberger • Arthur Konnerth
}

Received: 7 July 2006 / Accepted: 2 August 2006 / Published online: 18 October 2006

(C) Springer-Verlag 2006

\begin{abstract}
The precise understanding of the cellular and molecular basis of brain function requires the direct assessment of the activity of defined cells in vivo. A promising approach for such analyses is two-photon microscopy in combination with appropriate cell labeling techniques. Here, we review the multi-cell bolus loading (MCBL) method that involves the use of membranepermeant fluorescent indicator dyes. We show that this approach is useful for the functional analysis of clusters of neurons and glial cells in vivo. Work from our and other laboratories shows that the techniques that were previously feasible only in brain slices, like targeted patch clamp recordings from identified cells or pharmacological manipulations in confined brain regions, can now be used also in vivo. We also show that MCBL and two-photon imaging can be easily combined with other labeling techniques, particularly with those involving the use of genetically encoded, green-fluorescent-protein-based indicators. Finally, we examine recent applications of MCBL/two-photon imaging for the analysis of various brain regions, including the somatosensory and the visual cortex.
\end{abstract}

Keywords Calcium imaging - Two-photon microscopy Bolus loading · Functional architecture of neural networks

O. Garaschuk · R.-I. Milos • C. Grienberger • N. Marandi •

H. Adelsberger $\cdot$ A. Konnerth $(\bowtie)$

Institut für Neurowissenschaften,

Technische Universität München,

Biedersteinerstr. 29,

80802 Munich, Germany

e-mail: arthur.konnerth@1rz.tum.de

\section{Introduction}

Our understanding of the function of neural circuits in situ has benefited greatly from data obtained using two versatile techniques that were introduced 25 years ago: (1) the 'gigaseal' whole-cell patch clamp technique [1] and (2) the use of fluorescent indicator dyes [2]. Thus, neural networks in culture and/or brain slices are often studied either by means of $\mathrm{Ca}^{2+}$ imaging (after staining the cells with membranepermeant $\mathrm{Ca}^{2+}$ indicator dyes; for review see [3]) or by means of simultaneous patch-clamp recordings of connected neurons (for review, see [4, 5]). With the development of two-photon laser scanning microscopy [6], such studies became feasible even in vivo in anesthetized and, potentially, also in awake animals.

The initial in vivo studies combined two-photon calcium imaging with microelectrode $[7,8]$ or whole-cell patchclamp $[9,10]$ recordings. The microelectrodes or the patch pipettes were used not only for recording electrical signals from the cells of interest, but also, and equally important, for filling the cells with a calcium indicator dye, thus allowing high-resolution $\mathrm{Ca}^{2+}$ imaging in neurons and their processes. The use of membrane-permeant $\mathrm{Ca}^{2+}$ indicator dyes in vivo was introduced by Stosiek et al. [11]. This technique, termed multi-cell bolus loading (MCBL), enabled the targeted labeling of intact neuronal circuits in the living animal. The technique is applicable in various neuronal tissues and in a variety of species from lower vertebrates to mammals [12-18]. When combined with appropriate detection techniques, like two-photon laser scanning microscopy and/or brain endoscopy $[19,20]$, it allows the monitoring of both the 'macroscopic' function of brain circuits [20] and the 'microscopic' behavior of individual cells $[11,13]$. In this paper, we review recent data obtained with high-resolution in vivo $\mathrm{Ca}^{2+}$ imaging of 
neural circuits. We provide some new technical aspects of cell staining, describe approaches used to identify different cell types, and illustrate new applications arising from the combination of MCBL with other techniques.

\section{The MCBL approach}

Figure 1a illustrates an experimental arrangement used for in vivo MCBL. A dye ejection pipette, similar to those used for patch clamp recordings, containing a concentrated solution of a $\mathrm{Ca}^{2+}$ indicator dye (for example, Oregon
Green 488 BAPTA-1 acetoxymethyl ester [OG-1 AM]) is inserted into the brain through a small skull opening, and the dye is pressure-ejected into the brain area of interest. Within the brain, the dye diffuses into the cells and becomes hydrolyzed by endogenous esterases [2]. This procedure results in a rather uniform staining of cells within the targeted area (Fig. 1b). Originally we used $1 \mathrm{mM}$ of the indicator dye for the pressure ejection [11]. Recent data, however, have shown that a dye concentration of $100 \mu \mathrm{M}$ often produces similarly good results [21]. Other groups adapted our technique and used similar recipes for in vivo staining of cortical neurons in rats and a

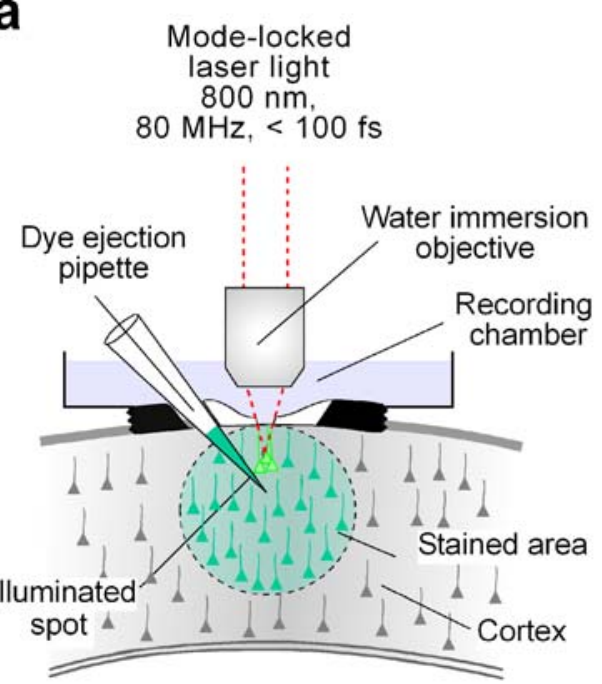

b

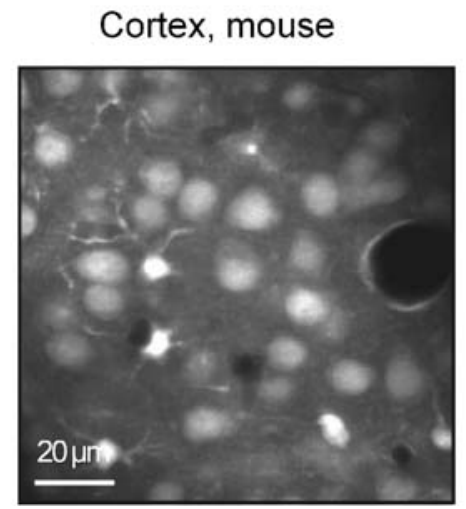

C

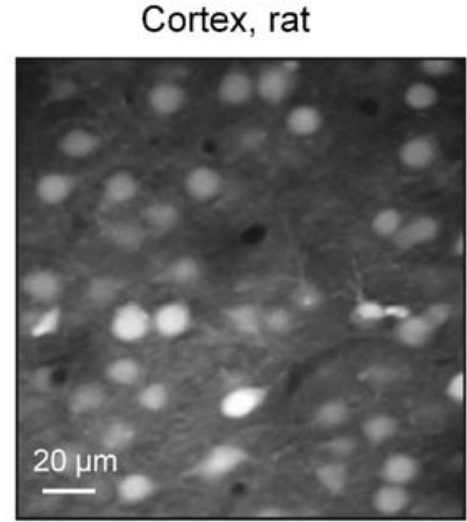

d

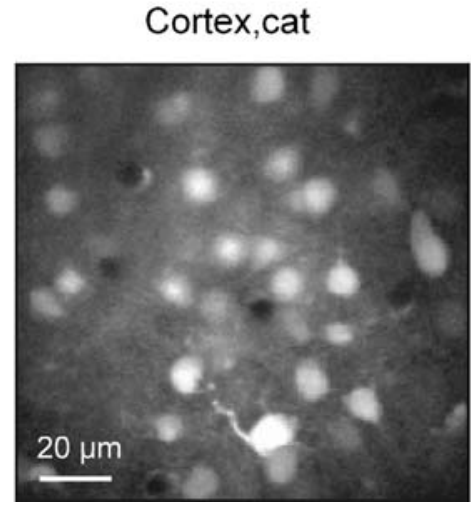

e

Cerebellum, rat

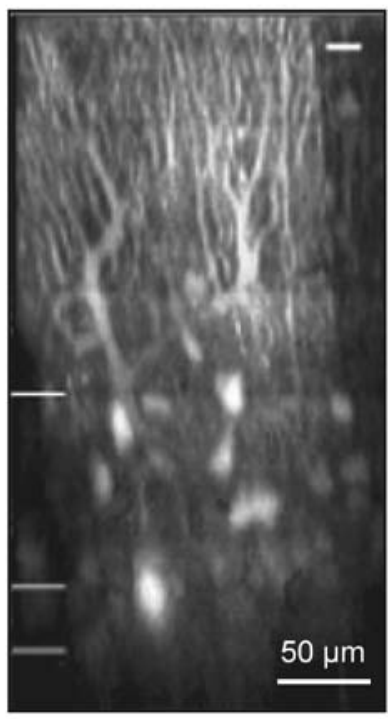

f

Spinal cord, Zebrafish

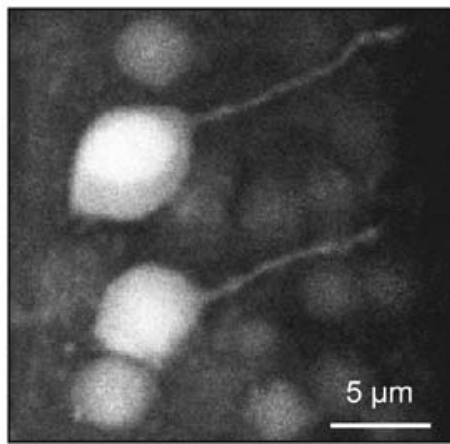

Fig. $1 \mathrm{MCBL}$ enables in vivo staining of neural networks in different species. a Schematic drawing of the experimental arrangement. Reproduced, with permission from Macmillan Publishers Ltd, from [21]. b-f In vivo images of stained cells in the cerebral cortex of a mouse (b), a rat (c), and a cat (d), as well as in the rat cerebellum (e) and in the spinal cord of a zebrafish larva (f). The cells in $\mathbf{b}-\mathbf{e}$ were stained with OG-1 AM and those in $\mathbf{f}$ with Fura PE3 AM. All images were obtained using two-photon laser scanning microscopy and are reproduced (with permission from Macmillan Publishers Ltd; National Academy of Sciences USA, copyright 2003, 2005; and the American Physiological Society) from references $[11,13,15,16]$, respectively. Note that both dyes stained all structures within a respective tissue; the only dark areas correspond to many small and one large $\mathbf{b}$ brain vessels. Here and below, all imaged preparations were stained using $\mathrm{MCBL}$ 
cats (Fig. 1c and d; [13]) and for dye labeling of rat cerebellar neurons (Fig. 1e; [15]). As already mentioned, the staining protocol is also applicable in lower vertebrates and was used, for example, for staining neurons in the spinal cord (Fig. 1f; [16]), olfactory bulb [17], and tectum [18] of zebrafish larvae. Interestingly, unlike other common protocols for labeling brain tissue with AM esters of $\mathrm{Ca}^{2+}$ indicator dyes [22], MCBL-based staining shows little age dependence and can be used not only for staining newborn and juvenile tissues but also for staining adult and even aged tissues [21].

Figure 2a shows the time course of an MCBL-based staining of the mouse visual cortex with Fura PE3 AM. The left panel of Fig. 2a illustrates a very early time point, immediately after dye ejection, in which the dye is located extracellularly. Within a few minutes, the dye starts to accumulate in the cells and is gradually removed from the extracellular space (Fig. 2a, middle and right panel). This removal process is the result of the cellular uptake of the dye and, importantly, the clearing of the extracellular space by the vascular system. To estimate the kinetics of the removal process, we pressure-ejected the membrane-impermeant fluorescent dye Alexa Fluor 594 into the mouse cortex and monitored its removal by the use of two-photon imaging (Fig. 2b). The removal process had a double exponential time course, with the mean decay time constants of $2.3 \pm 0.1$ and $13.3 \pm 0.7 \mathrm{~s}$ ( $n=33$ samples), respectively (Fig. 2c and d). In conclusion, dye removal from the extracellular space under in vivo conditions is very efficient and rapid, contributing to the good contrast between stained cells and the surrounding tissue.

\section{Identification of different cell types in vivo}

The MCBL procedure leads to the staining of virtually all cells in the targeted brain area. Although glial cells tend to accumulate higher concentration of indicator dyes $[11,23]$, their unequivocal identification requires the use of a specific marker and multicolor imaging. It was recently reported that glial and neuronal cells can be easily separated in vivo by using the specific glial marker sulforhodamine 101 [14]. Sulforhodamine 101 emits light in the red portion of the spectrum, and, therefore, it can be easily used in combination with any common $\mathrm{Ca}^{2+}$ indicator (e.g. OG-1 AM, Fura 2 AM, etc.). Glial cells stained both with OG-1 AM and sulforhodamine 101 appear yellow on the merged image (Fig. 3a), while neurons stained with OG-1 AM only appear green. To simplify and speed-up the staining procedure, we coejected both indicator dyes from the same pipette and simultaneously labeled the cells with sulforhodamine 101 and OG-1 AM [21].

Although separation of neurons and glial cells can be easily achieved, it is still rather difficult to discriminate between different types of neurons. One method of celltype-specific labeling involves the use of mutant mice expressing a specific fluorescent marker as, for example, enhanced green fluorescent protein (EGFP). This genetically encoded indicator was used in a variety of transgenic mice to mark GABAergic interneurons in general [24, 25], as well as parvalbumin- [26] or somatostatin-positive (Fig. 3b; [27]) interneuronal subtypes. Figure $3 \mathrm{~b}$ shows an example of an EGFPlabeled somatostatin-positive GABAergic cell (blue) in the mouse visual cortex stained with OG-1 AM (green).

A certain degree of cell specificity can also be achieved when using MCBL and confining dye delivery, as good as possible, to specific anatomical subregions. For example, for studying $\mathrm{Ca}^{2+}$ signals in the dendrites of layer 5 pyramidal neurons of the rat motor cortex (Fig. 3c), Kerr et al. [12] ejected the indicator dye at the level of layer 5 (650-750 $\mu \mathrm{m}$ below the pia). One hour after dye ejection, the dendrites of layer 5 cells became discernable at the level of layer $2 / 3$ and were studied using two-photon imaging.

\section{Targeted whole-cell patch clamp recordings in MCBL-stained tissues}

Originally, in vivo whole-cell patch clamp recordings in the mammalian brain were introduced as a 'blind' approach [28-31]. Thereby, the patch pipette is placed in the brain area of interest (e.g. within a given cortical area at a given depth) and is then slowly advanced forwards to hit a cell on its way. This approach gives good results if one aims at recording from any cell belonging to an abundant cell population. For recordings from cells belonging to a specific subclass of neurons, Margrie et al. [32] introduced a few years ago the socalled two-photon targeted patching approach. This procedure combines whole-cell patch clamp recordings with in vivo two-photon imaging of EGFP-positive neurons. An EGFP-positive neuron and a patch pipette filled with a fluorescent intracellular solution are brought into close proximity under the visual control using twophoton imaging (see also [33]). This allows in vivo whole-cell patch clamp recordings from defined cells, such as, for example, parvalbumin-positive GABAergic neurons [32]. The basic requirement for the two-photon targeted patching is the ability to visualize and preselect a cell of interest before a whole-cell recording configura- 
a

1 min after dye injection

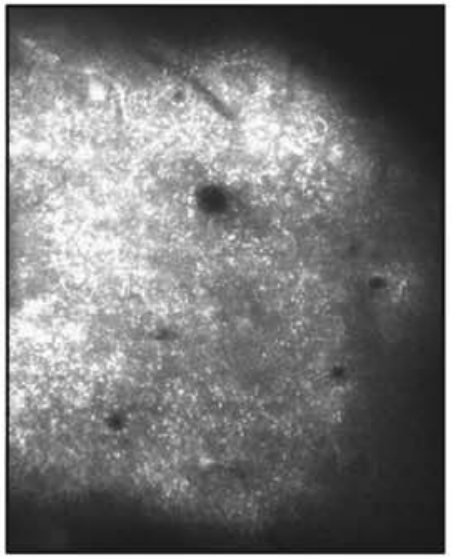

$5 \mathrm{~min}$

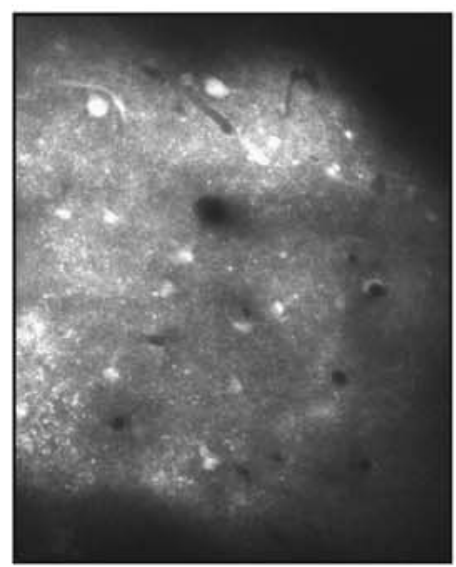

$20 \min$

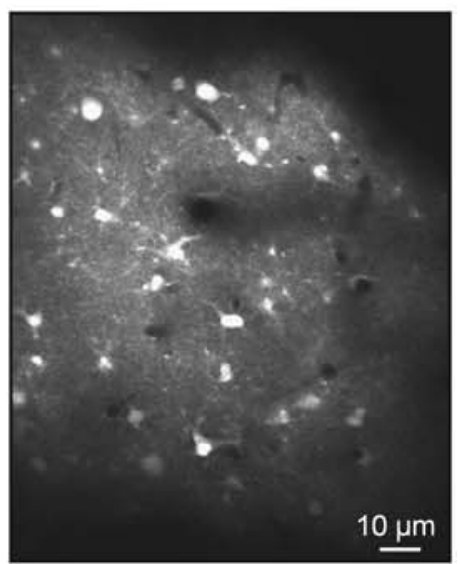

b Red channel: (Alexa Fluor 594)
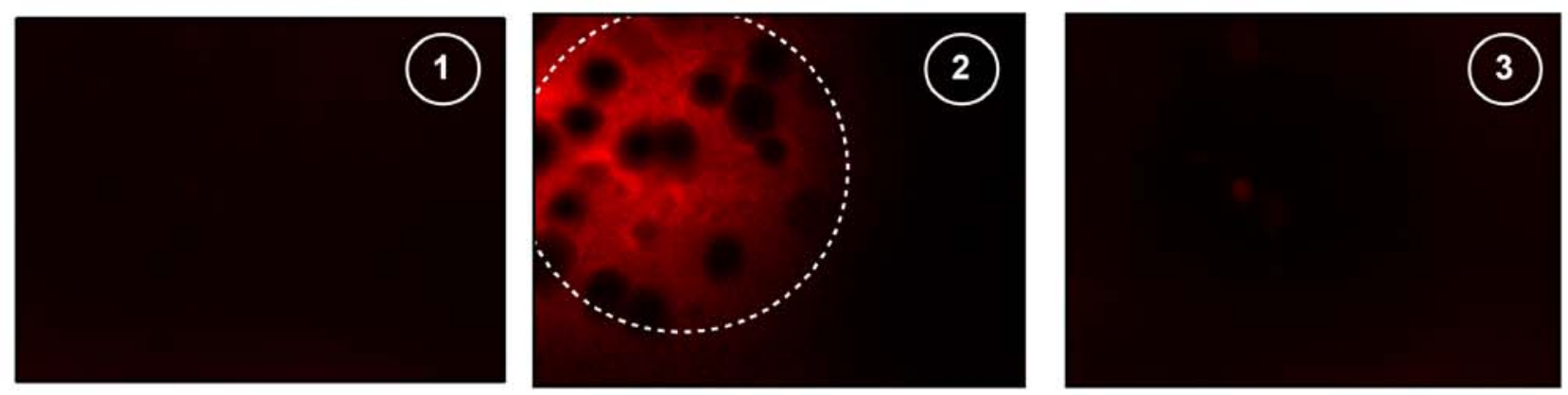

\section{Merged}
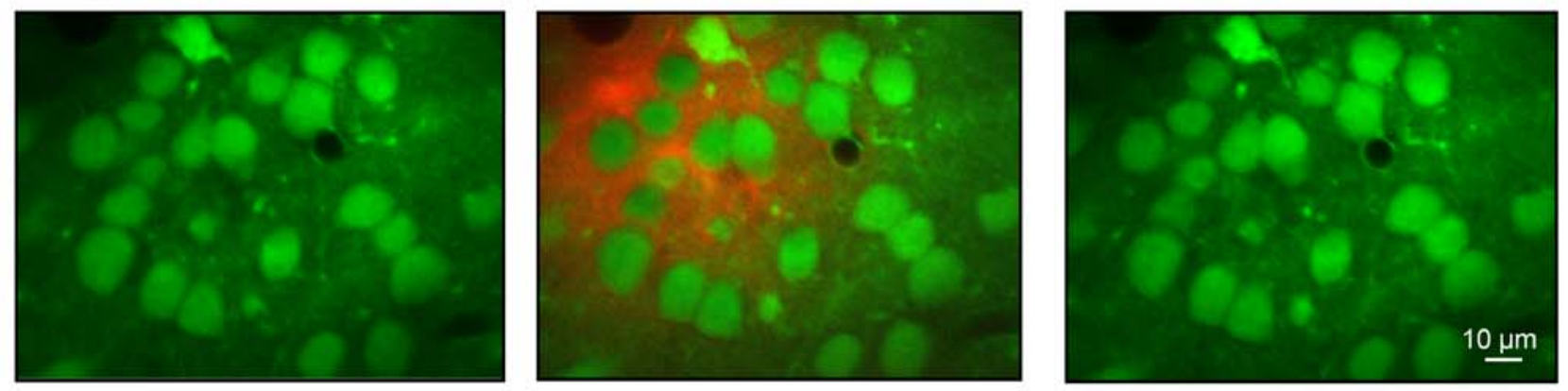

C

(2)

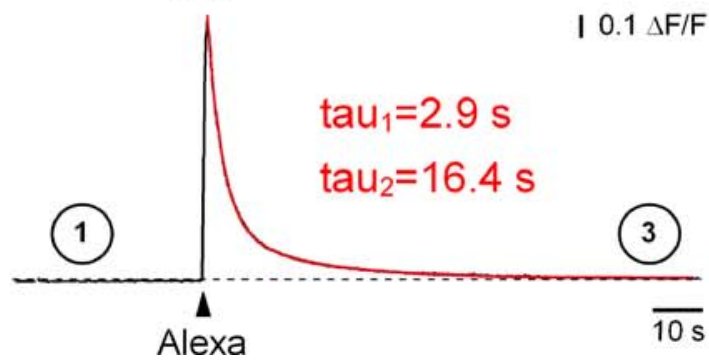

d

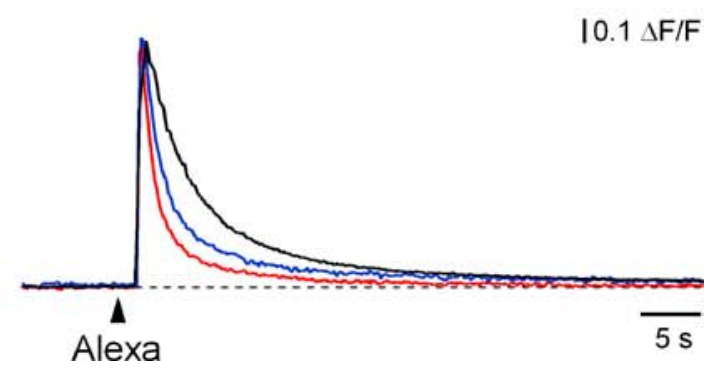


Fig. 2 Removal of extracellular dye molecules by microcirculation. a Images of layer $2 / 3$ cells in the mouse visual cortex taken in vivo 1,5 , and $20 \mathrm{~min}$ after a bolus injection of Fura PE3 AM. Note gradual removal of the dye from the extracellular space and an increasing brightness of individual cells. b In vivo images of the mouse visual cortex obtained before (1) during (2) and after (3) a $500 \mathrm{~ms}$ long injection of a red fluorescent dye Alexa Fluor 594 into the extracellular space (upper panel). Merged images on the lower panel show the fluorescence spot caused by Alexa injection $($ red $)$ in relation to individual cortical cells present in this region (stained with OG-1 AM, green). c The time course of the Alexa 594-based fluorescence transient. Numbers on the trace show the time points at which images in b were taken. d Three Alexa 594-based fluorescence transients, each obtained in a separate experiment, covering the entire range of the kinetics observed

tion is established. As shown in Fig. 4, a similar procedure can be used with MCBL-based staining. In these examples, a neuron (Fig. $4 \mathrm{a}-\mathrm{c}$ ) and a glia cell (Fig. 4d,e) were patched under visual control and identified based on their morphology and, more importantly, on how they responded to sulforhodamine 101 staining (Fig. 4d). The electrical responses recorded subsequently in the whole-cell configuration showed the behavior characteristic for neurons (Fig. 4b and c; up- and-down states [34]) and glia cells (Fig. 4e; [35]), respectively. In addition to the ability to select cells based on anatomical and/or molecular markers, MCBL allows to preselect the cells for targeted patching based on their calcium signaling properties.

\section{Somatic calcium signaling in vivo requires action potential firing}

By conducting simultaneous cell-attached electrical recordings and two-photon $\mathrm{Ca}^{2+}$ imaging in neurons stained with OG-1 AM in the rat somatosensory/motor cortex (Fig. 5a), Kerr et al. [12] showed that the probability of detecting a $\mathrm{Ca}^{2+}$ transient associated with a single action potential is as high as 97\%. The probability of detecting short bursts of two to four action potentials was even higher, approaching almost $100 \%$. In vivo $\mathrm{Ca}^{2+}$ transients evoked by single action potentials had mean amplitudes of approximately $10 \%$ (Fig. 5b) and mean decay time constants of $800 \mathrm{~ms}$ [12]. Similar results were also obtained in the mouse visual cortex $(O$. a

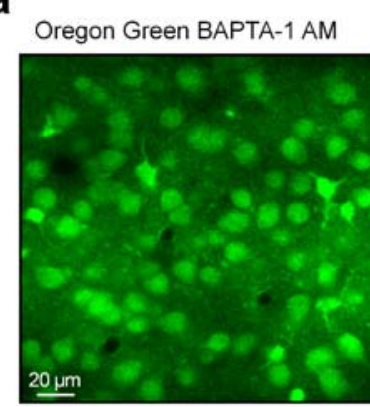

b

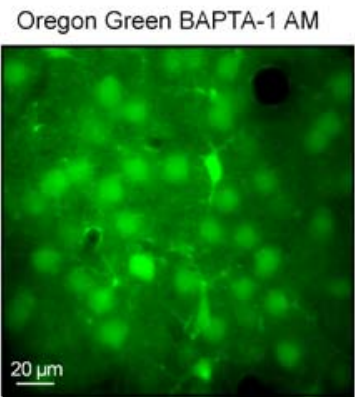

Sulforhodamine 101

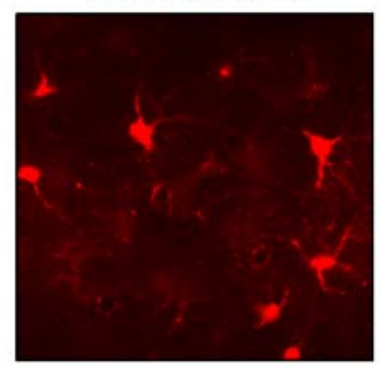

green fluorescent protein

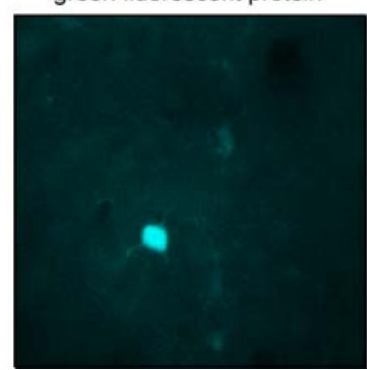

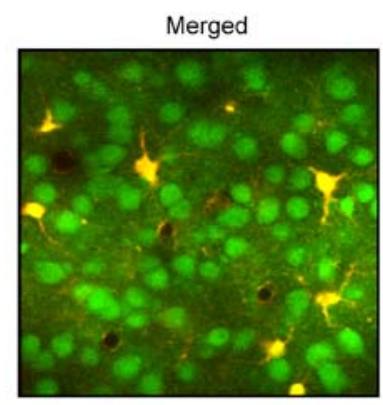

Merged

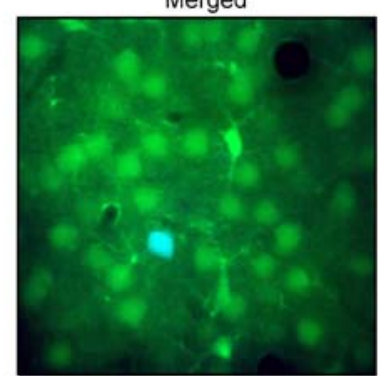

C Oregon Green BAPTA-1 AM

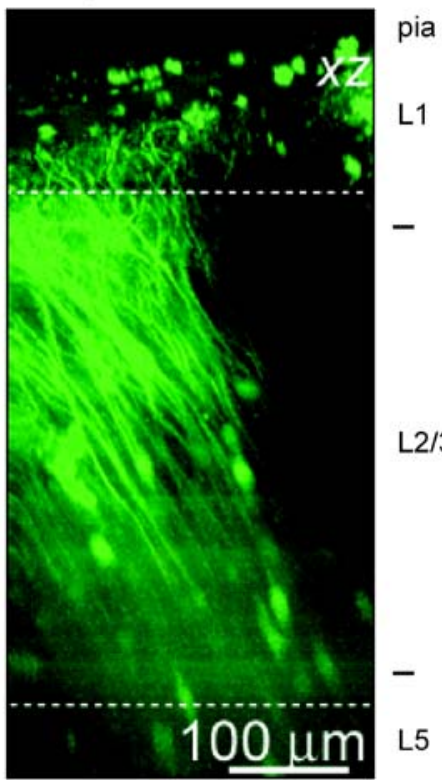

Fig. 3 Imaging of identified cell types. a Microphotographs of layer $2 / 3$ cells in the mouse visual cortex stained with MCBL technique using a dye mixture containing OG-1 AM and a glial marker sulforhodamine 101. The fluorescence of OG-1 AM was directed to the green channel (left) and the fluorescence of sulforhodamine 101 to the red one (middle). The merged image on the right shows neurons in green and glial cells in yellow. b Microphotographs illustrating OG-1 AM-based staining of layer $2 / 3$ cells (left) in a transgenic mouse

expressing EGFP (middle) selectively in somatostatin-positive GABAergic interneurons. The merged image on the right shows all cells in green and a somatostatin-positive interneuron in light blue. c A side projection of dendrites of layer 5 pyramidal neurons stained with OG-1 AM. a, c Reproduced (with permission from Macmillan Publishers Ltd; National Academy of Sciences USA, copyright 2005) from $[12,21]$, respectively 
a

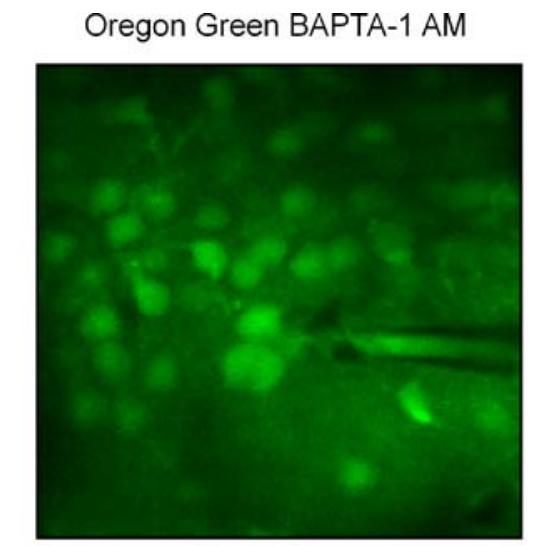

b

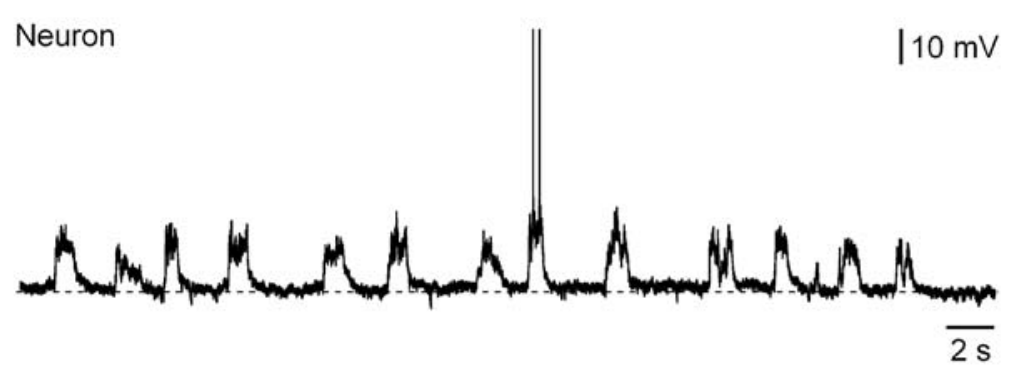

Alexa Fluor 594

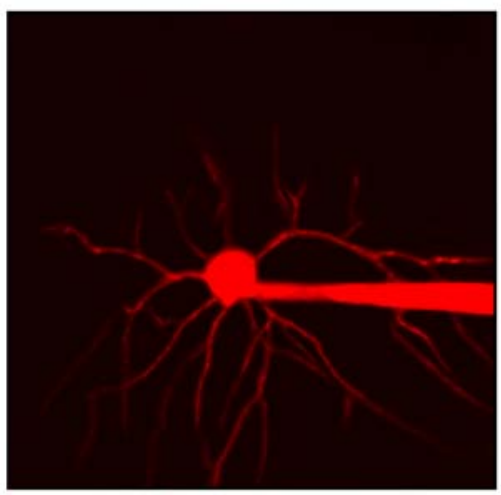

Merged

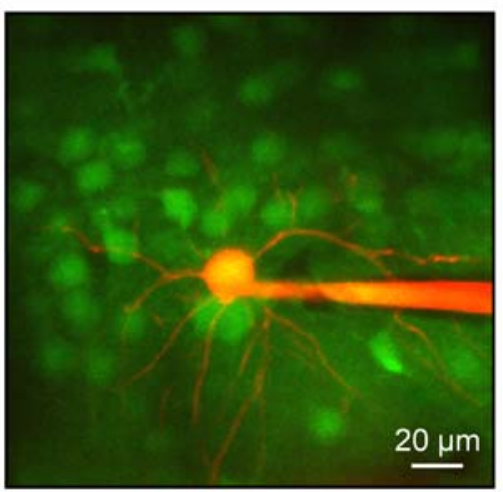

C

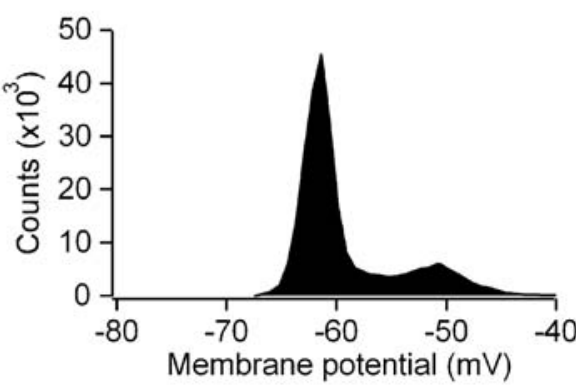

d

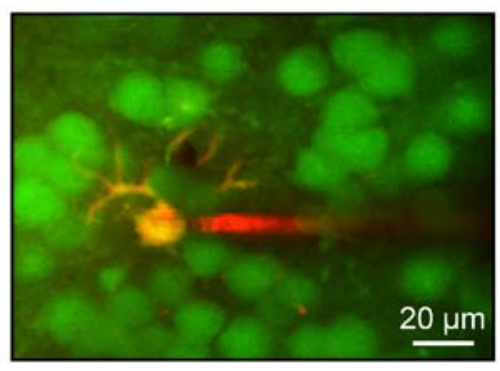

e

Glia

I $2 \mathrm{mV}$

Fig. 4 Targeted in vivo patch-clamp analysis using MCBL. a A microphotograph of layer $2 / 3$ cells stained with OG-1 AM (green channel, left). A neuron in the middle of the image was patched with a pipette containing Alexa Fluor 594 (red channel, middle). The image on the right is an overlay of the two images. b Whole-cell membrane potential recordings from the neuron in a. c A histogram of the membrane potential measurements in $\mathbf{b}$ showing two peaks at $-51 \mathrm{mV}$ (up state) and $-62 \mathrm{mV}$ (down state). d An overlay image showing OG-1 AM stained neurons in green and a patched glial cell filled with Alexa Fluor 594 in red. Before patching, the cell was labeled with S101. e Whole-cell recordings of the membrane potential of the glial cell shown in $\mathbf{d}$

concentration in MCBL stained cells is too low (approximately $20 \mu \mathrm{M}$; [11]) for dendritic recordings.

\section{In vivo pharmacology}

Although in vivo preparations are, in general, less accessible for controlled pharmacological manipulations as compared to cell cultures and tissue slices, there are several different techniques available for the pharmacological treatment of brain cells in vivo. Most often, drugs are administrated in 


\section{a In vivo}
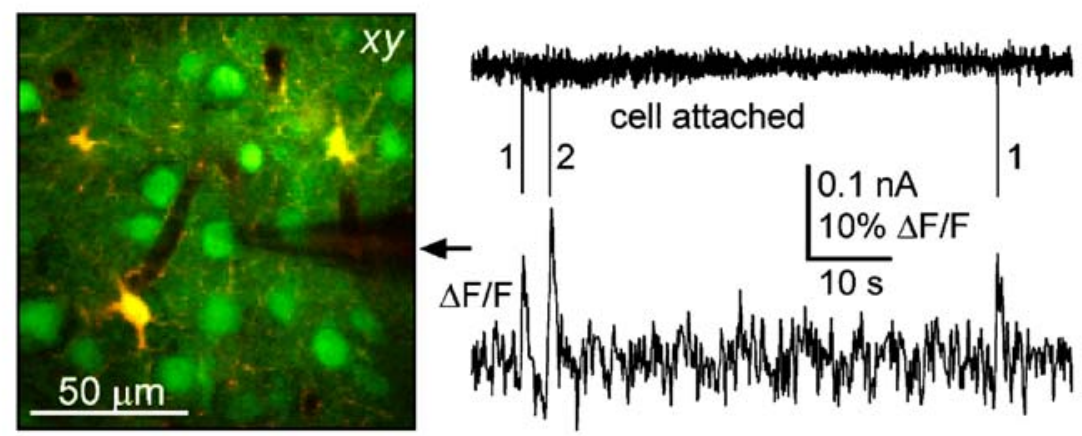

\section{C}

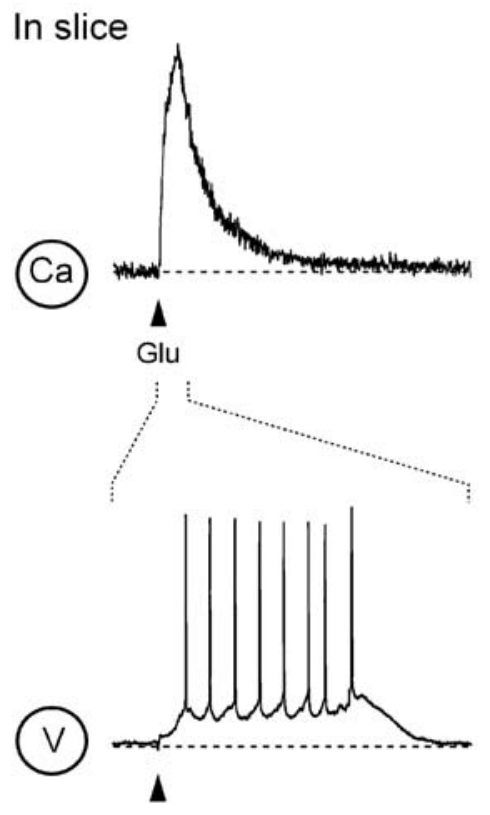

b

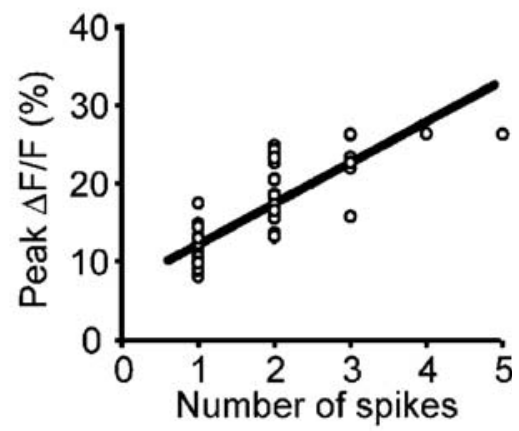

$10.2 \Delta \mathrm{F} / \mathrm{F}$

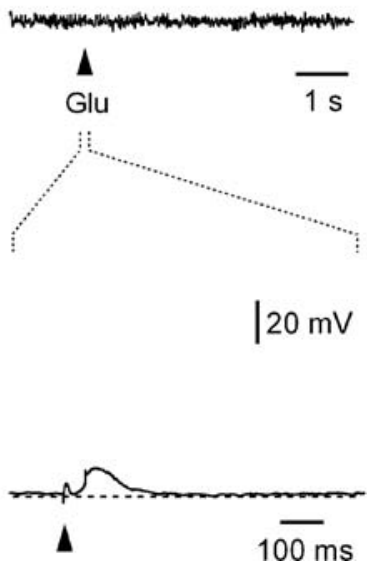

Fig. 5 Somatic $\mathrm{Ca}^{2+}$ signals in MCBL-stained cells require action potentials. a Left panel: a merged image of layer $2 / 3$ cells in the rat somatosensory cortex stained in vivo with OG-1 AM (green) and sulforhodamine 101 (red). Neurons are green and astrocytes are yellow. Right panel: a simultaneous recording of action potentials in the cell-attached configuration (upper trace) and associated $\mathrm{Ca}^{2+}$ transients (lower trace) obtained from the neuron in the middle. The

vivo via intravenal or intraperitoneal injections. The drugs used in such experiments have to be able to cross the bloodbrain barrier; their action is delayed and their concentration at the site of action is largely unknown. In addition, such treatments often cause systemic side effects. Therefore, the systemic drug administration has strong limitations when studying fast cellular responses. A convenient alternative method, which is particularly useful when performing imaging experiments with single cell resolution, is the local application of drugs directly to the cells of interest (Fig. 6). In experiments using MCBL, the craniotomy used for dye loading can be also used for the insertion of an iontophoresis or a pressure-application pipette. As shown in Fig. $6 \mathrm{c}$ position of the patch pipette is indicated by an arrow. b Amplitudes of in vivo calcium transients plotted as a function of the number of action potentials detected in simultaneous cell-attached recordings. a, b Reproduced, with permission from National Academy of Sciences USA, copyright 2005, from [12]. c Glutamate-evoked $\mathrm{Ca}^{2+}$ transients and corresponding changes in the membrane potential recorded in a cortical slice obtained from a brain stained in vivo with OG-1 AM

and $\mathrm{d}$, such applications can exert their action in highly confined brain regions, with a spherical shape and a diameter of around $100 \mu \mathrm{m}$. The use of a recording chamber, as that illustrated in Fig. 1a, allows an even simpler method for drug application. Drugs can be simply added to preheated artificial cerebrospinal fluid, which is used for continuous perfusion. This approach is similar to the bath application of drugs in conventional brain slice experiments. We found that under in vivo conditions, the small craniotomy used for MCBL-based cell staining is sufficiently large to allow an effective access of drugs to the brain parenchyma. In our experience, water-soluble drugs (e.g. the NMDA receptor antagonist 2-amino-5- 
Fig. 6 In vivo pharmacology. a, b In vivo $\mathrm{Ca}^{2+}$ recordings from layer $2 / 3$ cells of the mouse somatosensory cortex stained with OG-1 AM. The cells (marked with the respective numbers in the corresponding image) were stimulated either with an iontophoretic application of $10 \mathrm{mM}$ glutamate (a) or with an iontophoretic application of external saline (b). c, $\mathbf{d ~ C a}{ }^{2+}$ transients in layer $2 / 3$ cells of the mouse visual cortex (stained with OG-1 $\mathrm{AM}$ and marked with corresponding numbers in $\mathbf{c}$ ) caused by a local iontophoretic coapplication of $25 \mu \mathrm{M}$ Alexa Fluor 594 and $100 \mathrm{mM}$ glutamate. The circle in $\mathbf{c}$ delineates the area in which glutamateevoked $\mathrm{Ca}^{2+}$ transients were detected a
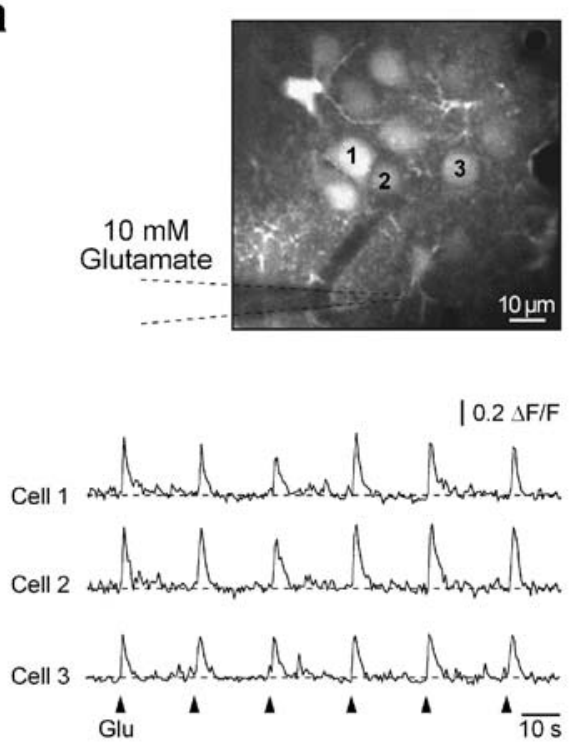

C

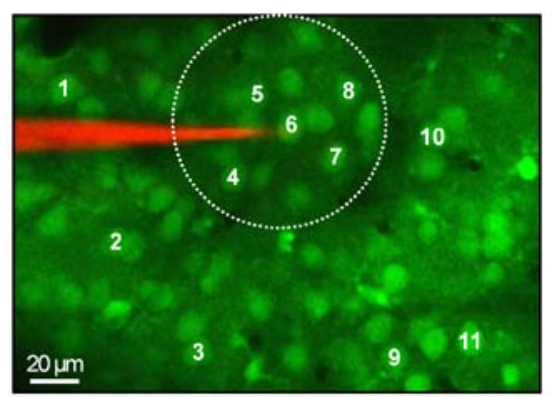

b

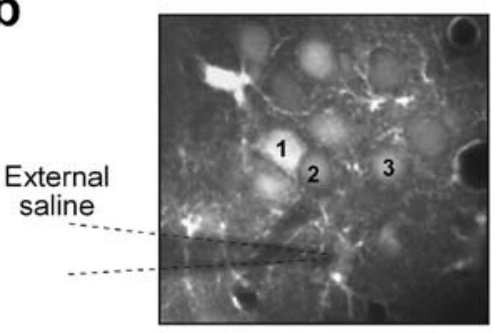

$0.2 \Delta \mathrm{F} / \mathrm{F}$
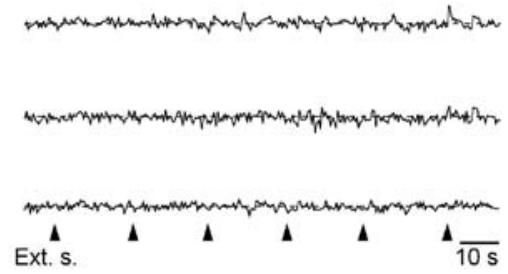

d

$10.8 \Delta \mathrm{F} / \mathrm{F}$

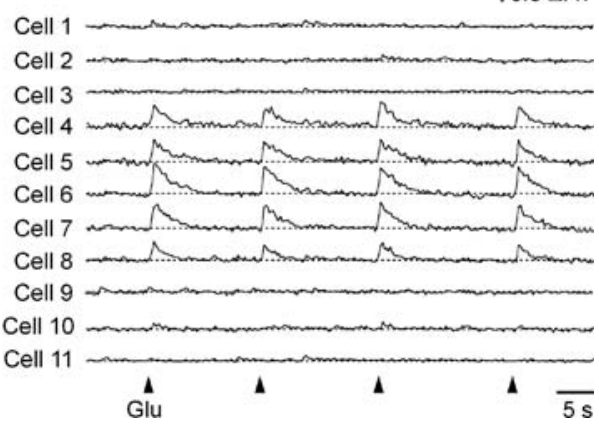

phosphonopentanoic acid [APV] or the sodium channel blocker tetrodotoxin [TTX]) start acting within the intact brain as soon as they are present in the recording chamber and, thus, within time frames that are comparable to those observed in brain slices. However, to achieve in vivo drug effects similar to those observed in slices, a two- to threefold increase in the concentration of the drug is required. The use of lipophilic drugs (e.g. the voltagegated $\mathrm{Ca}^{2+}$ channel blocker nitrendipine or the AMPA receptor antagonist CNQX) turned out to be more difficult. The required drug dosages were higher, most probably because of the poor diffusion properties of these substances.

\section{Monitoring sensory-driven neuronal activity with single cell resolution}

To this end, MCBL and two-photon imaging were used (a) for the characterization of spontaneous and sensory-driven activity in the somatosensory and motor cortices of rats and mice (Fig. 7a; [11, 12]), (b) for monitoring light-evoked responses in the mouse visual cortex (Fig. 7b), and (c) for the characterization of direction selectivity of the layer $2 / 3$ neurons in the visual cortex of rats and cats (Fig. 7c; [13]). In zebrafish larvae, the approach was used for the analysis of light-evoked responses in the optic tectum [18], odorevoked activity patterns in the olfactory bulb [17], and air puff-evoked $\mathrm{Ca}^{2+}$ signals in spinal cord neurons [16].

Two-photon imaging studies in rodent primary sensory cortices have established that the coding of spontaneous as well as sensory-driven activity in the upper cortical layers is sparse. Thus, only $10 \%$ of neurons participated in the spontaneous up states in rat somatosensory cortex [12]. Similarly, rather few cells responded to orientations of moving bars in rat visual cortex [13]. In contrast, the percentage of responsive cells in cat visual cortex was rather high, reaching even $100 \%$ in some experiments [13].

Another interesting feature revealed by two-photon imaging of neuronal networks in vivo is the heterogeneous distribution of activity in space and time across individual 
Mouse barrel cortex
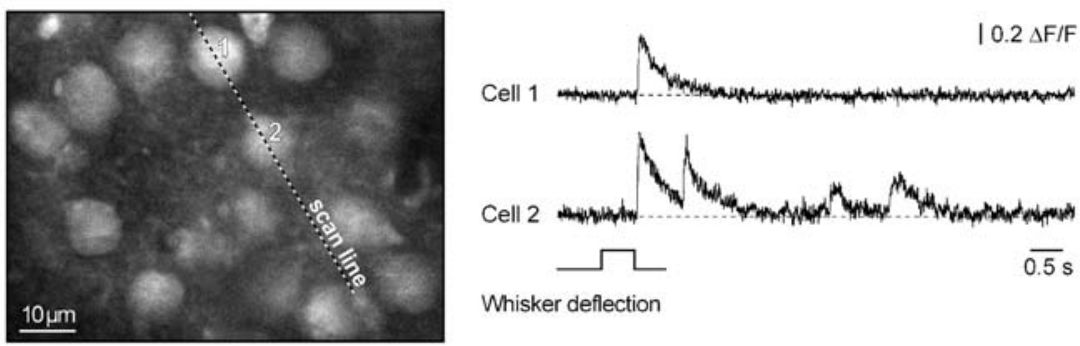

C

\section{Cat visual cortex}
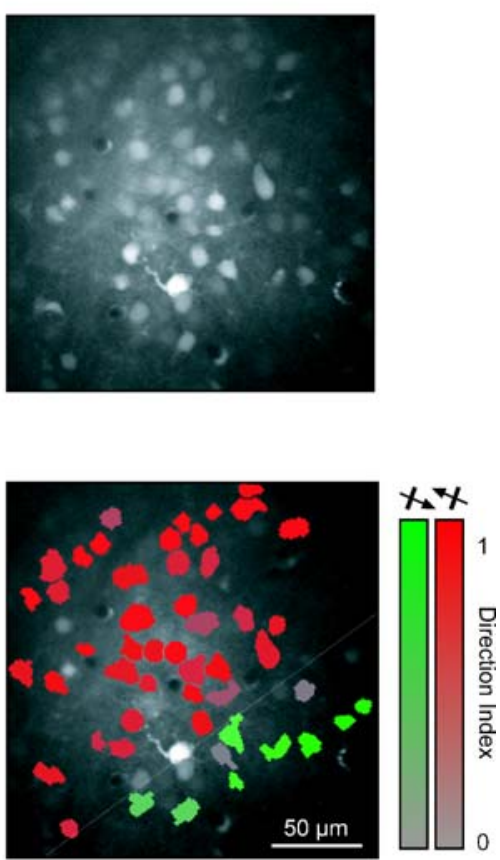

ㅁ.

b

Mouse visual cortex

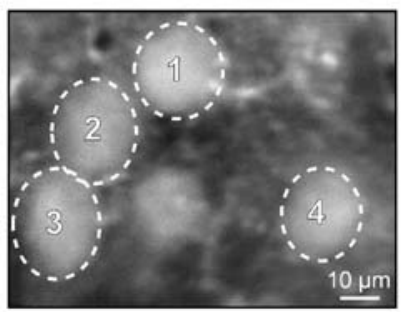

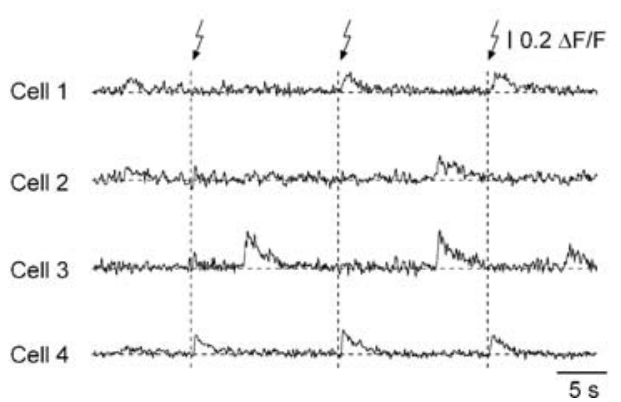

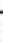

Fig. 7 Sensory-driven $\mathrm{Ca}^{2+}$ transients in individual cortical neurons. a Individual neurons in the mouse barrel cortex (left) and the corresponding $\mathrm{Ca}^{2+}$ transients (right) evoked by the deflection of the majority of whiskers at the contralateral side of the snout. The transients were recorded using the line-scan mode $(5 \mathrm{~ms} / \mathrm{line})$. The position of the scanned line is indicated. b Individual neurons in the mouse visual cortex (left) and the corresponding $\mathrm{Ca}^{2+}$ transients (right) evoked by brief light flashes. Light flashes were applied every
$10 \mathrm{~s}$ (indicated as a dotted line). $\mathbf{c}$ A high-resolution image of the cat visual cortex (upper panel). On the lower panel, all cells responding to a given direction of the visual stimulus were color-coded in red and green. The cells responding to both directions are displayed as gray, according to their direction index (see color scale on the right). a Reproduced, with permission from National Academy of Sciences USA, copyright 2003, from [11]. c Reproduced, with permission from Macmillan Publishers Ltd, from [13] neurons. For example, continuously changing 'mosaic' activation patterns were observed in rat and mouse somatosensory cortex during spontaneous [12] as well as sensory-driven [11] activity. These data indicated that such activities are not generated by a particular subset of neurons, but rather are produced by dynamically reorganizing neuronal subpopulations. Interestingly, the results concerning the organization of the orientation- and direction-selectivity maps at a single cell level show species specificity. Thus, in the optic tectum of zebrafish larvae as well as in the rat visual cortex, direction- or orientationselectivity maps are locally disordered with neighboring cells, often highly tuned to different directions and/or orientations $[13,18]$. In contrast, in the cat visual cortex, orientation- and direction-selectivity maps are highly organized (Fig. 7c; [13]). Orientation and direction selectivity varies slowly over the distance; the transitions between different preferred directions are smooth and ordered with each cell responding similarly to its nearest neighbors. Interestingly, the boundaries between neuronal clusters responding to different directions are extremely narrow $(20-50 \mu \mathrm{m})$ and are populated by cells responding rather equally to both directions (Fig. 7c).

\section{Monitoring $\mathrm{Ca}^{2+}$ signals in awake behaving animals}

To measure macroscopic properties of neural networks in nonanesthetized animals, Adelsberger et al. [20] combined MCBL with in vivo brain microendoscopy. The tip of a thin flexible optic fiber $(\varnothing=200 \mu \mathrm{m}$; numerical aperture $=0.48)$ was implanted into the brain region stained with OG-1 AM (Fig. 8a) and was used both for excitation of the fluorescent dye and for the collection of the emitted light. The use of a single detector (photomultiplier or avalanche photodiode) allowed recording a compound $\mathrm{Ca}^{2+}$ signal from all cells within the illuminated volume, thus severely reducing the susceptibility of recordings to movement artifacts. This in vivo microendoscope was recently used to record spontaneous $\mathrm{Ca}^{2+}$ waves in the cortex of nonanesthetized mouse pups (Fig. 8b). The waves occurred mainly during sleep 
a

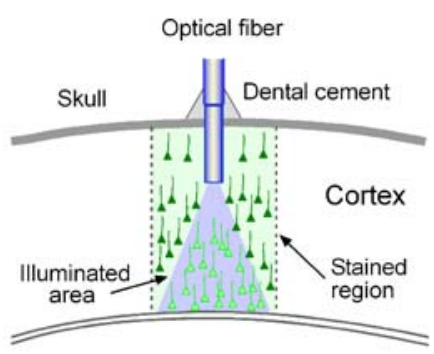

C

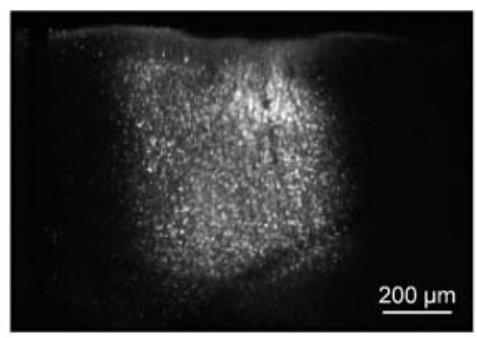

b

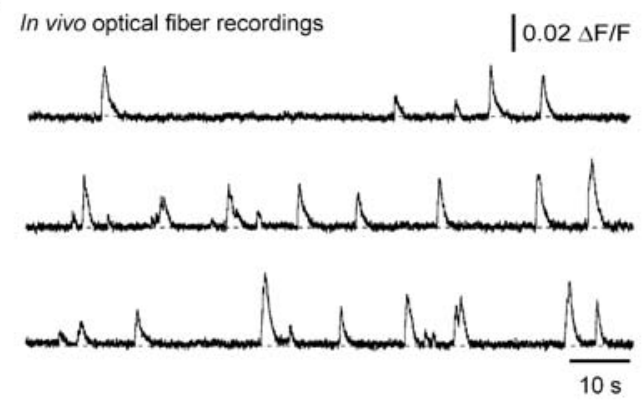

d

Two-photon imaging in slice
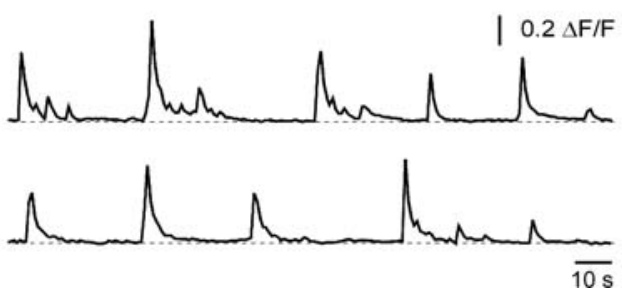

e

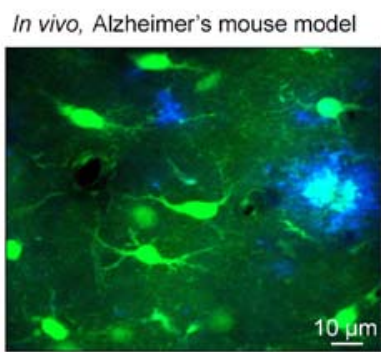

Green: Oregon Green BAPTA-1 AM Blue: Thioflavine S

f

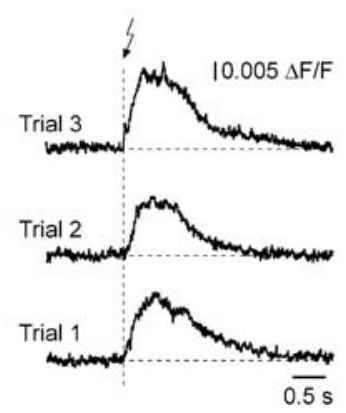

Fig. 8 In vivo brain microendoscopy. a A schematic drawing illustrating an implanted optical fiber. $\mathbf{b}$ In vivo recordings of spontaneous cortical $\mathrm{Ca}^{2+}$ waves in a nonanesthetized newborn mouse. $\mathbf{c}, \mathbf{d}$ A twophoton image of the in vivo stained cortical area (c), where the $\mathrm{Ca}^{2+}$ waves shown in $\mathbf{d}$ were recorded from. e A high-resolution in vivo image of the layer 1 in the visual cortex of a mouse model of

like resting states and vanished or became inhibited during animal's movements [20]. Remarkably, similar $\mathrm{Ca}^{2+}$ waves were present in cortical slices obtained from mice stained in vivo (Fig. 8c and d). They closely resembled the early network oscillations initially found in cortical slices of newborn rats [38].

In addition to monitoring $\mathrm{Ca}^{2+}$ signals in awake, behaving animals, the microendoscopic approach can be performed anywhere in the brain, even in deep and hidden regions. However, its limitation is that it currently allows just a single point detection. Spatially resolved recordings may be obtained either through the implantation of an array of fibers, or through the substitution of a single optical fiber by fiber bundles [39], and/or by using gradient refractive index fibers [40].

\section{Monitoring $\mathrm{Ca}^{2+}$ signals in aged and diseased brain}

It is difficult to establish a good experimental model for studying neuronal aging in vitro because of the high fragility of aged neuronal tissue. By contrast, in vivo studies, like the ones using MCBL, are feasible also in aged animals [21]. Figure 8e displays cortical cells in vivo in the visual cortex of a 1-year-old mouse mutant, which represents a mouse model of Alzheimer's disease. These
Alzheimer's disease [41]. Cells are stained with OG-1 AM (green) and amyloid depositions are stained with thioflavine $\mathrm{S}$ (blue). f Lightevoked population $\mathrm{Ca}^{2+}$ transients recorded with an endoscopic fiber in the visual cortex of a mouse model of Alzheimer's disease. Cortical cells were stained with OG-1 AM. a-d Reproduced, with permission from Macmillan Publishers Ltd, from [20]

mice overexpress a human amyloid precursor protein (APP) with the Swedish double mutation (at positions 670/671) that is associated with a familiar form of Alzheimer's disease [41]. As a result of the mutation, the cortex is enriched with accumulations of the amyloid- $\beta$ protein, socalled dense core plaques. The plaques represent a histological hallmark of Alzheimer's disease [42]. For two-photon in vivo imaging studies, the plaques can be stained with specific fluorescent markers like, for example, thioflavine $\mathrm{S}$ [43]. We found that the diffusion of thioflavine $\mathrm{S}$ within the brain is rather restricted, and, therefore, the in depth staining of the brain tissue is better achieved by the bolus ejection technique (Fig. 8e; O. Garaschuk, R.I. Milos, and A. Konnerth, unpublished observations). The in vivo functional properties of neuronal networks in mutant animals can be studied both at the 'macroscopic' level using brain endoscopy (Fig. 8f) and at the level of individual neurons when using two-photon imaging (Fig. 8e).

\section{Conclusions}

Two-photon $\mathrm{Ca}^{2+}$ imaging using targeted bulk loading of $\mathrm{Ca}^{2+}$ indicators is a useful approach for high-resolution in vivo imaging of network function. The advantages of the 
approach include the relatively high temporal resolution (frame rates of up to $100 / \mathrm{s}$ ), the good spatial resolution allowing the discrimination of single cells, and its high versatility that allows its use in a variety of animal models and at different ages. It is foreseeable, however, that the development of genetically encoded fluorescent protein sensors with improved properties will open exciting new possibilities in the nearest future [44-46]. Genetically encoded indicators, not just for calcium but also for other second messengers (e.g. [47-49]), can, in principle, be targeted to specific subclasses of neurons or even to small neuronal subcompartments, like dendrites and dendritic spines. The combination of bolus loading techniques with various methods like targeted expression of genetically encoded indicators will soon open entirely new avenues for the in vivo analysis of brain function.

Acknowledgements This study was supported by grants of the Deutsche Forschungsgemeinschaft (SFB 391 and SFB 596) and the Bundesministerium für Bildung und Forschung (NGFN-2). R.I.M. was supported by Marie Curie Fellowship. We thank M. Staufenbiel and D. Abramowski for APP mice.

\section{References}

1. Hamill OP, Marty A, Neher E, Sakmann B, Sigworth FJ (1981) Improved patch-clamp techniques for high-resolution current recording from cells and cell-free membrane patches. Pflügers Arch 391:85-100

2. Tsien RY (1981) A non-disruptive technique for loading calcium buffers and indicators into cells. Nature 290:527-528

3. Cossart R, Ikegaya Y, Yuste R (2005) Calcium imaging of cortical networks dynamics. Cell Calcium 37:451-457

4. Feldmeyer D, Lubke J, Silver RA, Sakmann B (2002) Synaptic connections between layer 4 spiny neurone-layer $2 / 3$ pyramidal cell pairs in juvenile rat barrel cortex: physiology and anatomy of interlaminar signalling within a cortical column. J Physiol 538:803-822

5. Silberberg G, Grillner S, LeBeau FE, Maex R, Markram H (2005) Synaptic pathways in neural microcircuits. Trends Neurosci 28:541-551

6. Denk W, Strickler JH, Webb WW (1990) Two-photon laser scanning fluorescence microscopy. Science 248:73-76

7. Svoboda K, Denk W, Kleinfeld D, Tank DW (1997) In vivo dendritic calcium dynamics in neocortical pyramidal neurons. Nature 385:161-165

8. Svoboda K, Helmchen F, Denk W, Tank DW (1999) Spread of dendritic excitation in layer $2 / 3$ pyramidal neurons in rat barrel cortex in vivo. Nat Neurosci 2:65-73

9. Waters J, Helmchen F (2004) Boosting of action potential backpropagation by neocortical network activity in vivo. J Neurosci 24:11127-11136

10. Waters J, Larkum M, Sakmann B, Helmchen F (2003) Supralinear $\mathrm{Ca}^{2+}$ influx into dendritic tufts of layer $2 / 3$ neocortical pyramidal neurons in vitro and in vivo. J Neurosci 23:8558-8567

11. Stosiek C, Garaschuk O, Holthoff K, Konnerth A (2003) In vivo two-photon calcium imaging of neuronal networks. Proc Natl Acad Sci USA 100:7319-7324
12. Kerr JN, Greenberg D, Helmchen F (2005) Imaging input and output of neocortical networks in vivo. Proc Natl Acad Sci USA 102:14063-14068

13. Ohki K, Chung S, Ch'ng YH, Kara P, Reid RC (2005) Functional imaging with cellular resolution reveals precise micro-architecture in visual cortex. Nature 433:597-603

14. Nimmerjahn A, Kirchhoff F, Kerr JND, Helmchen F (2004) Sulforhodamine 101 as a specific marker of astroglia in the neocortex in vivo. Nat Methods 1:31-37

15. Sullivan MR, Nimmerjahn A, Sarkisov DV, Helmchen F, Wang SS (2005) In vivo calcium imaging of circuit activity in cerebellar cortex. J Neurophysiol 94:1636-1644

16. Brustein E, Marandi N, Kovalchuk Y, Drapeau P, Konnerth A (2003) 'In vivo' monitoring of neuronal network activity in zebrafish by two-photon $\mathrm{Ca}^{2+}$ imaging. Pflügers Arch 446: 766-773

17. Li J, Mack JA, Souren M, Yaksi E, Higashijima S, Mione M, Fetcho JR, Friedrich RW (2005) Early development of functional spatial maps in the zebrafish olfactory bulb. J Neurosci 25: 5784-5795

18. Niell CM, Smith SJ (2005) Functional imaging reveals rapid development of visual response properties in the zebrafish tectum. Neuron 45:941-951

19. Mehta AD, Jung JC, Flusberg BA, Schnitzer MJ (2004) Fiber optic in vivo imaging in the mammalian nervous system. Curr Opin Neurobiol 14:617-628

20. Adelsberger H, Garaschuk O, Konnerth A (2005) Cortical calcium waves in resting newborn mice. Nat Neurosci 8:988990

21. Garaschuk O, Milos RI, Konnerth A (2006) Targeted bulk-loading of fluorescent indicators for two-photon brain imaging in vivo. Nat Prot 1:380-386

22. Yuste R (2000) Loading brain slices with AM esters or calcium indicators. In: Yuste R, Lanni F, Konnerth A (eds) Imaging: a laboratory manual. Cold Spring Harbor Press, Cold Spring Harbor, New York, pp 34.31-34.39

23. Hirase H, Qian L, Bartho P, Buzsaki G (2004) Calcium dynamics of cortical astrocytic networks in vivo. PLoS Biol 2:E96

24. Lopez-Bendito G, Sturgess K, Erdelyi F, Szabo G, Molnar Z, Paulsen O (2004) Preferential origin and layer destination of GAD65-GFP cortical interneurons. Cereb Cortex 14:1122-1133

25. Tamamaki N, Yanagawa Y, Tomioka R, Miyazaki J, Obata K, Kaneko T (2003) Green fluorescent protein expression and colocalization with calretinin, parvalbumin, and somatostatin in the GAD67-GFP knock-in mouse. J Comp Neurol 467:60-79

26. Meyer AH, Katona I, Blatow M, Rozov A, Monyer H (2002) In vivo labeling of parvalbumin-positive interneurons and analysis of electrical coupling in identified neurons. J Neurosci 22: 7055-7064

27. Oliva AA Jr, Jiang M, Lam T, Smith KL, Swann JW (2000) Novel hippocampal interneuronal subtypes identified using transgenic mice that express green fluorescent protein in GABAergic interneurons. J Neurosci 20:3354-3368

28. Pei X, Volgushev M, Vidyasagar TR, Creutzfeldt OD (1991) Whole cell recording and conductance measurements in cat visual cortex in-vivo. NeuroReport 2:485-488

29. Ferster D, Jagadeesh B (1992) EPSP-IPSP interactions in cat visual cortex studied with in vivo whole-cell patch recording. J Neurosci 12:1262-1274

30. Brecht M, Sakmann B (2002) Dynamic representation of whisker deflection by synaptic potentials in spiny stellate and pyramidal cells in the barrels and septa of layer 4 rat somatosensory cortex. J Physiol 543:49-70

31. Margrie TW, Brecht M, Sakmann B (2002) In vivo, lowresistance, whole-cell recordings from neurons in the anaesthetized and awake mammalian brain. Pflügers Arch 444:491-498 
32. Margrie TW, Meyer AH, Caputi A, Monyer H, Hasan MT, Schaefer AT, Denk W, Brecht M (2003) Targeted whole-cell recordings in the mammalian brain in vivo. Neuron 39:911-918

33. Komai S, Denk W, Osten P, Brecht M, Margrie TW (2006) Two-photon targeted patching (TPTP) in vivo. Nat Prot 1: 647-652

34. Petersen CC, Hahn TT, Mehta M, Grinvald A, Sakmann B (2003) Interaction of sensory responses with spontaneous depolarization in layer 2/3 barrel cortex. Proc Natl Acad Sci USA 100: $13638-13643$

35. Amzica F (2002) In vivo electrophysiological evidences for cortical neuron-glia interactions during slow $(<1 \mathrm{~Hz})$ and paroxysmal sleep oscillations. J Physiol Paris 96:209-219

36. Smetters D, Majewska A, Yuste R (1999) Detecting action potentials in neuronal populations with calcium imaging. Methods 18:215-221

37. Kovalchuk Y, Eilers J, Lisman J, Konnerth A (2000) NMDA receptor-mediated subthreshold $\mathrm{Ca}^{2+}$ signals in spines of hippocampal neurons. J Neurosci 20:1791-1799

38. Garaschuk O, Linn J, Eilers J, Konnerth A (2000) Large-scale oscillatory calcium waves in the immature cortex. Nat Neurosci 3:452-459

39. Bharali DJ, Klejbor I, Stachowiak EK, Dutta P, Roy I, Kaur N, Bergey EJ, Prasad PN, Stachowiak MK (2005) Organically modified silica nanoparticles: a nonviral vector for in vivo gene delivery and expression in the brain. Proc Natl Acad Sci USA 102:11539-11544

40. Flusberg BA, Cocker ED, Piyawattanametha W, Jung JC, Cheung EL, Schnitzer MJ (2005) Fiber-optic fluorescence imaging. Nat Methods 2:941-950

41. Sturchler-Pierrat C, Abramowski D, Duke M, Wiederhold KH, Mistl C, Rothacher S, Ledermann B, Burki K, Frey P, Paganetti
PA, Waridel C, Calhoun ME, Jucker M, Probst A, Staufenbiel M, Sommer B (1997) Two amyloid precursor protein transgenic mouse models with Alzheimer disease-like pathology. Proc Natl Acad Sci USA 94:13287-13292

42. Alzheimer A (1911) Über eigenartige Krankheitsfälle des späteren Alters. Z Gesamte Neurol Psychiatr 4:356-386

43. Christie RH, Bacskai BJ, Zipfel WR, Williams RM, Kajdasz ST, Webb WW, Hyman BT (2001) Growth arrest of individual senile plaques in a model of Alzheimer's disease observed by in vivo multiphoton microscopy. J Neurosci 21:858-864

44. Hasan MT, Friedrich RW, Euler T, Larkum ME, Giese G, Both M, Duebel J, Waters J, Bujard H, Griesbeck O, Tsien RY, Nagai T, Miyawaki A, Denk W (2004) Functional fluorescent $\mathrm{Ca}^{2+}$ indicator proteins in transgenic mice under TET control. PLoS Biol 2:e163

45. Diez-Garcia J, Matsushita S, Mutoh H, Nakai J, Ohkura M, Yokoyama J, Dimitrov D, Knopfel T (2005) Activation of cerebellar parallel fibers monitored in transgenic mice expressing a fluorescent $\mathrm{Ca}^{2+}$ indicator protein. Eur $\mathrm{J}$ Neurosci 22:627-635

46. Mank M, Reiff DF, Heim N, Friedrich MW, Borst A, Griesbeck O (2006) A FRET-based calcium biosensor with fast signal kinetics and high fluorescence change. Biophys J 90:1790-1796

47. Yasuda R, Harvey CD, Zhong H, Sobczyk A, van Aelst L, Svoboda K (2006) Supersensitive Ras activation in dendrites and spines revealed by two-photon fluorescence lifetime imaging. Nat Neurosci 9:283-291

48. Zaccolo M, De Giorgi F, Cho CY, Feng L, Knapp T, Negulescu PA, Taylor SS, Tsien RY, Pozzan T (2000) A genetically encoded, fluorescent indicator for cyclic AMP in living cells. Nat Cell Biol 2:25-29

49. Gorbunova YV, Spitzer NC (2002) Dynamic interactions of cyclic AMP transients and spontaneous $\mathrm{Ca}^{2+}$ spikes. Nature 418:93-96 